\title{
The effect of prophylactic hemoclips on the risk of delayed post-endoscopic mucosal resection bleed for upper and lower gastrointestinal lesions: a retrospective cohort study
}

Karen Chang1', Brian S. Lee1, Timnit Tekeste', Andrew Nguyen', Mopelola Adeyemo', Agathon Girgis', Karl K. Kwok ${ }^{2}$, H. Michael Crowson ${ }^{3}$, Alicia O. Burris ${ }^{1}$, Rajeev Attam ${ }^{4}$, Charles T. Chaya ${ }^{5}$, Theodore E. Durbin ${ }^{6}$, Andrew Q. Giap ${ }^{6}$, Gordon C. Hunt ${ }^{7}$, John Iskander ${ }^{2}$, Kevin T. Kao ${ }^{4}$ and Brian S. Lim ${ }^{1,5^{*}}$

\begin{abstract}
Background: Endoscopic mucosal resection (EMR) is a minimally invasive procedure used for the treatment of lesions in the gastrointestinal (GI) tract. There is increased usage of hemoclips during EMR for the prevention of delayed bleeding. This study aimed to evaluate the effect of hemoclips in the prevention of delayed bleeding after EMR of upper and lower Gl tract lesions.

Method: This is a retrospective cohort study using the Kaiser Permanente Southern California (KPSC) EMR registry. Lesions in upper and lower GI tracts that underwent EMR between January 2012 and December 2015 were analyzed. Rates of delayed bleeding were compared between the hemoclip and no-hemoclip groups. Analysis was stratified by upper GI and lower Gl lesions. Lower Gl group was further stratified by right and left colon. We examined the relationship between clip use and several clinically-relevant variables among the patients who exhibited delayed bleeding. Furthermore, we explored possible procedure-level and endoscopist-level characteristics that may be associated with clip usage.

\footnotetext{
* Correspondence: Brian.s.lim@kp.org

'Department of Internal Medicine, School of Medicine, University of California, Riverside, 900 University Avenue, Riverside, CA 92521, USA

${ }^{5}$ Department of Gastroenterology, Kaiser Permanente Riverside Medical Center, 10800 Magnolia Avenue, Riverside, CA 92505, USA

Full list of author information is available at the end of the article
}

C C The Author(s). 2020 Open Access This article is licensed under a Creative Commons Attribution 4.0 International License, which permits use, sharing, adaptation, distribution and reproduction in any medium or format, as long as you give appropriate credit to the original author(s) and the source, provide a link to the Creative Commons licence, and indicate if changes were made. The images or other third party material in this article are included in the article's Creative Commons licence, unless indicated otherwise in a credit line to the material. If material is not included in the article's Creative Commons licence and your intended use is not permitted by statutory regulation or exceeds the permitted use, you will need to obtain permission directly from the copyright holder. To view a copy of this licence, visit http://creativecommons.org/licenses/by/4.0/ The Creative Commons Public Domain Dedication waiver (http://creativecommons.org/publicdomain/zero/1.0/) applies to the data made available in this article, unless otherwise stated in a credit line to the data. 
(Continued from previous page)

Results: A total of 18 out of 657 lesions (2.7\%) resulted in delayed bleeding: 7 (1.1\%) in hemoclip group and 11 $(1.7 \%)$ in no-hemoclip group ( $p=0.204)$. There was no evidence that clip use moderated the effects of the lesion size $(p=0.954)$ or lesion location ( $p=0.997)$ on the likelihood of delayed bleed. In the lower Gl subgroup, clip application did not alter the effect of polyp location (right versus left colon) on the likelihood of delayed bleed $(p=0.951)$. Logistic regression analyses showed that the clip use did not modify the likelihood of delayed bleeding as related to the following variables: use of aspirin/NSAIDs/anti-coagulants/anti-platelets, pathologic diagnoses (including different types of colon polypoid lesions), ablation, piecemeal resection. The total number of clips used was 901 at a minimum additional cost of $\$ 173,893$.

Conclusion: Prophylactic hemoclip application did not reduce delayed post-EMR bleed for upper and lower Gl lesions in this retrospective study performed in a large-scale community practice setting. Routine prophylactic hemoclip application during EMR may lead to significantly higher healthcare cost without a clear clinical benefit.

Keywords: Hemoclip, Endoscopic mucosal resection, Delayed bleed, Endoscopy, Colonoscopy, Polypectomy

\section{Background}

Endoscopic mucosal resection (EMR) is a wellestablished procedure used for the treatment of superficial lesions in the gastrointestinal (GI) tract not amenable for standard resection techniques. Before the advent of EMR, surgical resection was the treatment of choice, especially for large lesions. Compared to surgical resection, EMR is minimally invasive, less costly, has a faster recovery time, and maintains the normal functions of the GI tract [1]. Moreover, EMR has a high efficacy and safety profile with an acceptably low complication profile [1-6].

Bleeding is the most common complication of EMR $[7,8]$. The incidence of delayed bleeding, which can be from few days to several weeks post resection, varies from 1 to $6 \%$ [9-15]. Several risk factors have been reported to be associated with delayed bleeding: older age ( $\geq 75$ years), peri-procedural anticoagulation use, American Society of Anesthesiologist (ASA) classification scores of III or IV, larger lesion size ( $>40$ $\mathrm{mm})$, right-sided lesions and mucosal gap not closed by hemoclips [7, 16-19].

Although hemoclips are commonly utilized to prevent delayed bleeding, its application has been associated with conflicting results. While some studies have shown prophylactic clipping during EMR to be useful in preventing delayed bleed [20-22], other studies have shown no significant benefit [23-27]. In fact, upfront routine prophylactic clipping may result in improper resource utilization, including cost and time [27, 28].

There are numerous studies looking at the use of hemoclips for the prevention of post-polypectomy delayed bleeding in large colonic polyps [20, 21, 23-25], but there is a paucity of studies that examine the prophylactic use of hemoclips during EMR of upper GI lesions [22, 29]. In the present study, our aim is to analyze the efficacy of prophylactic hemoclip application to prevent post-EMR delayed bleed of both upper and lower GI lesions.

\section{Methods}

Study population and inclusion/exclusion criteria

The study was approved by the Kaiser Permanente Southern California (KPSC) Institutional Review Board (protocol number 10830). Kaiser Permanente Southern California is an integrated health system with 15 hospitals and 202 medical offices. Data from the KPSC EMR registry were reviewed to identify upper and lower GI lesions that underwent EMR between January 2012 and December 2015. All patients were over the age of 18. EMR procedures were performed by 12 interventional endoscopists across the region who have all undergone advanced endoscopy fellowship and routinely perform EMR as part of their practice. In addition to the primary outcome of delayed bleeding, the following variables were collected: age at diagnosis, gender, comorbidity (hypertension, diabetes, coronary artery disease, cerebrovascular accident, liver cirrhosis, and end stage renal disease), location of lesion, pathologic diagnoses, and usage of aspirin, nonsteroidal anti-inflammatory drugs (NSAIDs), anticoagulants, and antiplatelet agents. Exclusion criteria were as follows: (1) cases that were aborted due to non-lift sign, (2) aborted cases (prior to any resection) for any other reasons such as residual food and clinical instability, (3) ampullary lesions, and (4) cases where hemoclips were used for active intraprocedural bleeding and not for the sole purpose of prophylaxis.

\section{Definitions}

Definition of prophylactic clipping post-EMR was as follows: procedures in which hemoclips were used to prevent delayed bleeding and not for the purpose of hemostasis of active intraprocedural bleeding at the time of EMR. Delayed bleed was defined as any significant GI bleeding that occurred up to 30 days post EMR. This was determined by symptoms (e.g. hematochezia and melena), hemoglobin drop of more than $1 \mathrm{~g} / \mathrm{dL}$, and/or blood transfusion(s) required. Patients were captured through a combination of hospital admissions data via 
KPSC electronic medical record system and claims data (for patient admissions that occurred outside of KPSC network). If there was delayed bleeding, the following variables were examined: blood transfusion(s), hospital length of stay (intensive care unit/ICU versus non-ICU), need for repeat GI procedure, IR (interventional radiology) intervention, and surgical intervention.

For those procedures that indicated clip usage but did not note specific number of clips, we assumed that at least one clip was used. There were four different models of hemoclips used for the procedures included in the study. For cost analysis of the clip expense, we used the average cost of these different models of clips which was $\$ 193$.

\section{Statistical analysis}

Statistical analysis was conducted using SPSS 24. Descriptive analyses of baseline characteristics were performed with Student's t-test for continuous variables and chi-square test or Fisher's exact test for binary variables. All reported $p$ values had alpha 0.05 level of significance.

The primary unit of analysis in this study was lesion (level 1), which was nested within patient (level 2), who in turn was nested within endoscopist (level 3). We tested an unconditional multilevel binary logistic regression model to determine whether the likelihood of a bleed varied significantly at the level of patients and endoscopists. Results of the unconditional model revealed evidence of nonsignificant variation at these levels. We tested two additional two-level models - one with lesion nested within patient only and the other with lesion nested within endoscopist only. Both models yielded evidence of nonsignificant variation. Given this evidence of non-trivial variation at the patient and endoscopist levels (suggestive of an absence of clustering in the data), we ultimately relied on the single-level approach, i.e. at the lesion level, for statistical testing of relationships between delayed bleeding and other variables.

Fisher's exact tests were used to test the zero-order relationship between delayed-bleed and clip use, location in the GI tract (dichotomized as upper versus lower), and size of the lesion (dichotomized as $<20 \mathrm{~mm}$ versus $\geq 20 \mathrm{~mm}$ ). A one-sided test was utilized (under the conventional assumption that clip use would be associated with less delayed bleeding). The remaining tests involving lesion size and location variables were two-sided. Fisher's exact test was used to evaluate the relationship between delayed bleeding and use of medications, age (dichotomized as < 75 versus 275 ), whether or not the resection was performed in piecemeal, and use of ablation. We tested the relationship between delayed bleeding and number of clips, patient age (not dichotomized), and lesion size (not dichotomized) using point-biserial correlation.
We tested whether there was a relationship between delayed bleed and final pathologic diagnoses using a chisquare test of association. Because several categories were of low frequency, we carried out our analyses involving a subset of diagnoses that exhibited frequencies of 15 or greater. As such, our analysis involved 7 of the 20 diagnostic categories found in the original data, covering 595 (91\%) of the lesions.

The relationship between clip use and several additional clinically-relevant variables were examined among the 18 patients who exhibited a delayed bleed. We computed the point-biserial correlation between clip use versus no clip use and length of hospital stay. Next, we computed Fisher's exact tests and phi-coefficients to examine the relationship between clip use and need for repeat procedures and blood transfusion requirement.

Logistic regression analyses were carried out in order to explore whether clip use (or no use) might moderate relationships between delayed bleeding and other variables (location in the GI tract [upper versus lower GI], lesion size, pathologic diagnoses, and the use of aspirin, NSAIDs, anti-coagulants, and anti-platelets). In the binary logistic regression for the lower GI subgroup, Firth procedure was used given the low incidence of delayed bleed.

Finally, we utilized multilevel binary logistic regression to test the likelihood that at least one clip would be utilized during a procedure by a particular endoscopist, as well as to explore possible procedure-level (Level 1) and endoscopist-level (Level 2) characteristics associated with clip usage during a procedure.

\section{Results}

\section{Details of EMR procedures}

Our analysis cohort was comprised of 620 procedures and 657 unique lesions, of which 175 (26.6\%) were in the upper GI tract and 482 (73.4\%) were in the lower GI tract. Twenty-nine procedures had multiple lesions (23 procedures with 2 lesions, 4 procedures with 3 lesions, 2 procedures with 4 lesions) and 591 procedures had a single lesion. The number of lesions in the prophylactic hemoclip group was 337 (51\%) and 320 (49\%) in the nohemoclip group. A total of 901 clips were deployed (average of 1.37 clips per lesion). The mean size of the lesions in the hemoclip group was $23.13 \mathrm{~mm}$ (range 1.2$100 \mathrm{~mm}$ ) and that of the no-hemoclip group was 27.1 $\mathrm{mm}$ (range $2-90 \mathrm{~mm}$ ), $p<0.001$. Baseline characteristics are listed in Table 1. The anatomic locations of the lesions are noted in Fig. 1.

\section{Hemoclip utilization and delayed bleeding}

A total of $18(2.7 \%)$ lesions resulted in delayed bleeding: 7 lesions (1.1\%) in hemoclip group and 11 lesions (1.7\%) in no-hemoclip group. Details of delayed bleeding cases 
Table 1 Baseline characteristics

\begin{tabular}{|c|c|c|c|}
\hline & Clip & No Clip & $p$ value \\
\hline Number of lesions & 337 (51\%) & $320(49 \%)$ & N/A \\
\hline Age [years, Mean (SD)] ${ }^{b}$ & $63.83(10.75)$ & $64.38(11.43)$ & 0.5281 \\
\hline $\operatorname{Sex}^{\mathrm{b}}$ & & & 0.5707 \\
\hline Male & 179 (53\%) & $176(55 \%)$ & \\
\hline Female & $158(47 \%)$ & $144(45 \%)$ & \\
\hline Lesion size [mm, Mean (SD)] & $23.13(14.90)$ & $27.10(23.13)$ & $<0.001$ \\
\hline Lesion location & & & 0.0894 \\
\hline Upper & $98(29 \%)$ & $74(23 \%)$ & \\
\hline Lower & 239 (71\%) & $246(77 \%)$ & \\
\hline \multicolumn{4}{|l|}{ Medications ${ }^{\mathrm{b}}$} \\
\hline Aspirin & $62(18.3 \%)$ & $56(17.5 \%)$ & 0.7903 \\
\hline NSAIDs & $31(9.3 \%)$ & $20(6.1 \%)$ & 0.1209 \\
\hline Anti-platelets & $6(1.8 \%)$ & $16(5.1 \%)$ & $0.0209^{\mathrm{a}}$ \\
\hline Anti-coagulants & $12(3.6 \%)$ & $9(2.9 \%)$ & $0.5968^{\mathrm{a}}$ \\
\hline \multicolumn{4}{|l|}{ Final pathologic diagnosis } \\
\hline Adenoma & 186 (55.19\%) & $196(61.25 \%)$ & 0.1157 \\
\hline Hyperplastic & $18(5.34 \%)$ & $10(3.13 \%)$ & 0.1598 \\
\hline Serrated Adenoma & $37(10.98 \%)$ & $29(9.06 \%)$ & 0.4140 \\
\hline Adenocarcinoma & 17 (5.04\%) & $36(11.25 \%)$ & 0.0035 \\
\hline Hamartoma & $1(0.30 \%)$ & $0(0.00 \%)$ & $>0.9999$ \\
\hline Barrett's & $5(1.48 \%)$ & $10(3.13 \%)$ & 0.1592 \\
\hline Barrett's Carcinoma & $4(1.19 \%)$ & $5(1.56 \%)$ & 0.7466 \\
\hline Pancreatic Heterotopia & $5(1.48 \%)$ & $1(0.31 \%)$ & 0.2175 \\
\hline Neuroendocrine/Carcinoid Tumor & $28(8.31 \%)$ & $8(2.50 \%)$ & 0.0011 \\
\hline Gastric Heterotopia of Rectum & $1(0.30 \%)$ & $0(0.00 \%)$ & $>0.9999$ \\
\hline Gastrointestinal Stromal Tumor & $6(1.78 \%)$ & $1(0.31 \%)$ & 0.1239 \\
\hline Granular Cell Tumor & $1(0.30 \%)$ & $5(1.56 \%)$ & 0.1145 \\
\hline Gastric Intestinal Metaplasia & $5(1.48 \%)$ & $2(0.63 \%)$ & 0.4517 \\
\hline Leiomyoma & $2(0.59 \%)$ & $1(0.31 \%)$ & $>0.9999$ \\
\hline Inflammatory & $4(1.19 \%)$ & $2(0.63 \%)$ & 0.6867 \\
\hline Lipoma & $6(1.78 \%)$ & $3(0.94 \%)$ & 0.5061 \\
\hline Squamous Cell Carcinoma & $0(0.00 \%)$ & $2(0.63 \%)$ & 0.2368 \\
\hline Hemangioma & $3(0.89 \%)$ & $0(0.00 \%)$ & 0.2494 \\
\hline Brunner's Gland Hyperplasia & $1(0.30 \%)$ & $1(0.31 \%)$ & $>0.9999$ \\
\hline Other & $7(2.08 \%)$ & $8(2.50 \%)$ & 0.7168 \\
\hline
\end{tabular}

${ }^{a}$ Anti-platelets and anti-coagulants are usually discontinued prior to EMR in majority of cases performed at the medical centers included although this information could not be adequately captured.

bescriptive analyses for patients' age, gender, and medication usage were performed at the patient/procedure level rather than lesion level.

are listed in Table 2. There was no statistically significant association between delayed post-EMR bleeding and use of prophylactic hemoclips, $p=0.204$, meaning prophylactic hemoclip deployment did not reduce the delayed bleed risk. The rate of delayed bleed did not change when the analysis was stratified by upper GI $(0$ lesions in hemoclip group and 1 lesion in no-hemoclip group, $p=0.248$ ) and lower GI (7 lesions in hemoclip group and 10 lesions in no-hemoclip group, $p=0.641$ ).

\section{Relationships between delayed bleeding and the remaining variables besides hemoclip application} There was a significant association between delayed bleeding and lesion size $(<20 \mathrm{~mm}$ versus $\geq 20 \mathrm{~mm}$, 


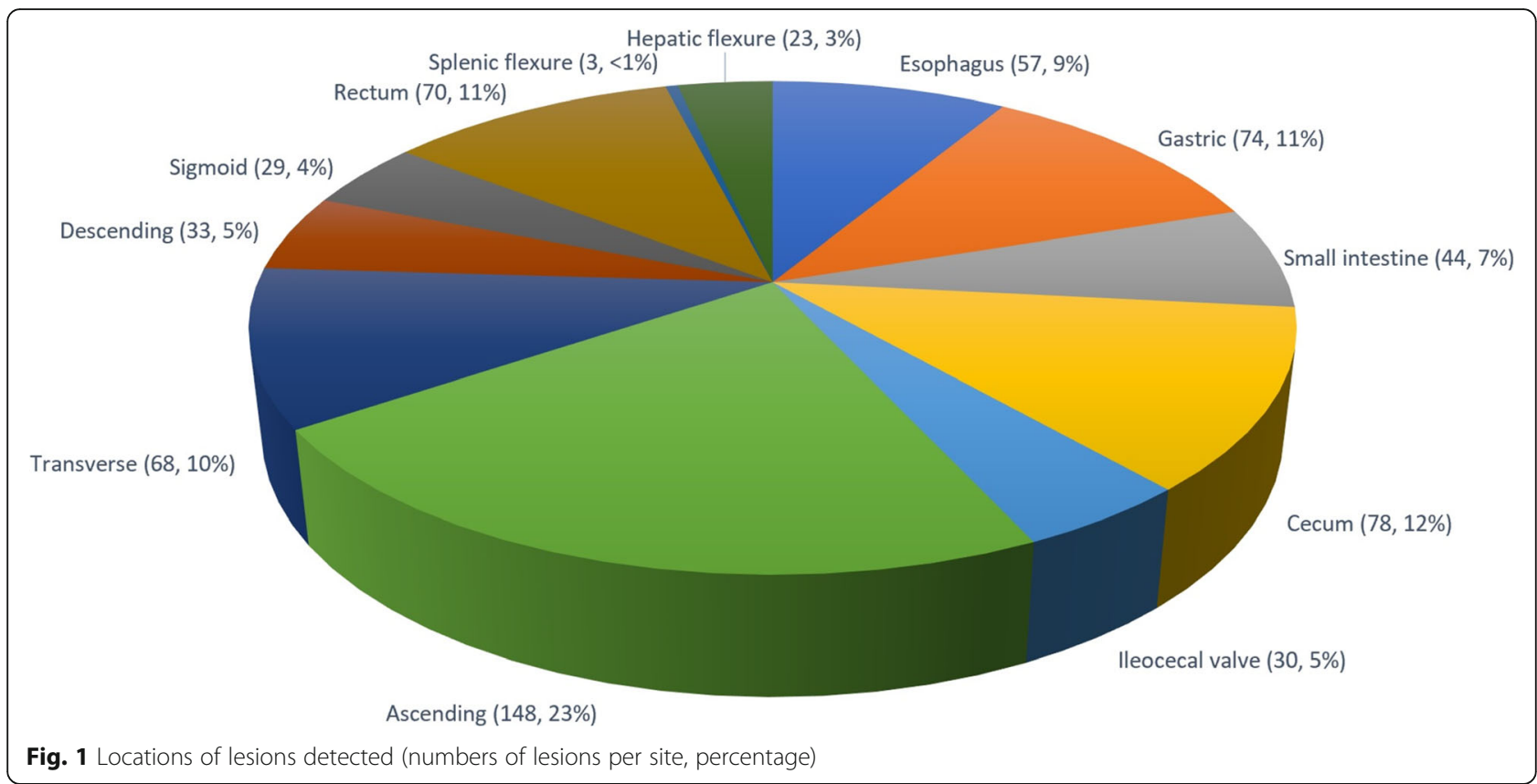

Table 2 Detailed descriptions of delayed bleeding cases

\begin{tabular}{|c|c|c|c|c|c|c|c|c|c|c|c|c|}
\hline \multirow{2}{*}{$\begin{array}{l}\text { Pt } \\
\text { \# }\end{array}$} & \multirow[t]{2}{*}{ Location $^{a}$} & \multirow[t]{2}{*}{$D x^{b}$} & \multirow[t]{2}{*}{ Clip } & \multicolumn{3}{|c|}{ Presentation } & \multicolumn{2}{|c|}{ Hospitalization } & \multicolumn{4}{|l|}{ Treatment } \\
\hline & & & & $\begin{array}{l}\text { Days post } \\
\text { EMR }\end{array}$ & $\begin{array}{l}\text { Gl Bleed } \\
\text { symptoms }\end{array}$ & $\begin{array}{l}\text { Hb decrease } \\
(\mathrm{g} / \mathrm{dL})\end{array}$ & $\begin{array}{l}\text { Total LOS } \\
\text { (days) }\end{array}$ & $\begin{array}{l}\text { ICU LOS } \\
\text { (days) }\end{array}$ & $\begin{array}{l}\text { Blood transfusion } \\
\text { (units) }\end{array}$ & Gl Procedure & $\mathbb{I R}$ & SRG \\
\hline 1 & 6 & 2 & Yes & 5 & Hematochezia & 4.8 & 3 & 0 & 0 & Colonoscopy & No & No \\
\hline 2 & 2 & 1 & No & 11 & Hematochezia & 5.0 & 4 & 0 & 0 & None & No & No \\
\hline 3 & 4 & 1 & Yes & 13 & Hematochezia & 1.7 & 2 & 0 & 0 & Colonoscopy & No & No \\
\hline 4 & 3 & 1 & Yes & 1 & Hematochezia & 3.8 & 4 & 0 & 4 & Colonoscopyce & No & No \\
\hline 5 & 2 & 1 & Yes & 8 & Hematochezia & 2.2 & 2 & 0 & 0 & None & No & No \\
\hline 6 & 7 & 4 & No & 0 & Hematochezia & 5.3 & 3 & 0 & 0 & Colonoscopy & No & No \\
\hline 7 & 6 & 1 & No & 4 & Hematochezia & 4.1 & 3 & 0 & 0 & Colonoscopy $^{c}$ & No & No \\
\hline 8 & 1 & 5 & No & 1 & Melena & 1.8 & 5 & 0 & 3 & $E G D^{c}$ & No & No \\
\hline 9 & 4 & 1 & No & 9 & Hematochezia & 3.5 & 3 & 0 & 2 & Colonoscopy $^{c}$ & No & No \\
\hline 10 & 3 & 1 & No & 1 & Hematochezia & 5.2 & 4 & 0 & 2 & Colonoscopy ${ }^{d}$ & No & No \\
\hline 11 & 5 & 1 & No & 3 & Hematochezia & 4.2 & 2 & 0 & 0 & Colonoscopy $^{\mathrm{c}, \mathrm{d}}$ & No & No \\
\hline 12 & 5 & 1 & No & 6 & Hematochezia & 1.7 & 1 & 0 & 0 & None & No & No \\
\hline 13 & 2 & 1 & Yes & 3 & Hematochezia & 1.5 & 3 & 0 & 2 & Colonoscopy $^{c}$ & No & No \\
\hline 14 & 4 & 1 & Yes & 13 & Hematochezia & 2.5 & 2 & 0 & 2 & Colonoscopy $^{d}$ & No & No \\
\hline 15 & 4 & 4 & No & 4 & Hematochezia & 2.2 & 2 & 0 & 0 & Colonoscopy & No & No \\
\hline 16 & 4 & 1 & No & 1 & Hematochezia & 2.4 & 4 & 0 & 0 & None & No & No \\
\hline 17 & 4 & 3 & No & 1 & Hematochezia & 2.5 & 1 & 0 & 0 & None & No & No \\
\hline 18 & 2 & 1 & Yes & 4 & Hematochezia & 2.8 & 3 & 0 & 2 & Colonoscopy $^{c}$ & No & No \\
\hline
\end{tabular}

atocation code: 1-Gastric, 2-Cecum, 3-lleocecal valve, 4-Ascending, 5-Transverse, 6-Rectum, 7-Splenic flexure.

${ }^{\mathrm{b} D x}$ (diagnosis) code: 1-Adenoma, 2-Hyperplastic, 3-Serrated adenoma, 4-Adenocarcinoma, 5-inflammatory

'Hemoclips applied during repeat colonoscopy/endoscopy for delayed bleed.

${ }^{\mathrm{d}}$ Thermal coagulation methods applied during repeat colonoscopy/endoscopy for delayed bleed.

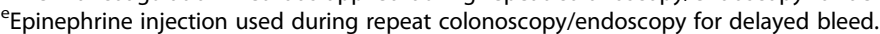

Pt Patient, Dx Diagnosis, EMR Endoscopic mucosal resection, Hb Hemoglobin, LOS Length of stay, ICU Intensive care unit, EGD Esophagogastroduodenoscopy, IR Interventional radiology, SRG Surgery. 
$p=0.045)$ and near significance between delayed bleeding and lesion location $(p=0.054)$. Delayed bleeding occurred more frequently in those cases involving larger lesions and in lower GI. When the lesion size was treated as a continuous variable (not dichotomized as $<20 \mathrm{~mm}$ versus $\geq 20 \mathrm{~mm}$ ), there was still a significant association between delayed bleeding and size $[\mathrm{r}(655)=0.09, p=0.02]$. Of the tests involving the various medications (aspirin, NSAIDs, antiplatelets, and anti-coagulants), only anti-coagulant use was significantly related to delayed bleed $(p=0.017)$. Procedures where ablative methods were used during EMR were associated with delayed bleeding ( $p=$ 0.036). There was no statistically significant relationship between delayed bleed and any of the following variables: underlying conditions (hypertension, diabetes, coronary artery disease, cerebrovascular accident, cirrhosis, end-stage renal disease), age $(<75$ versus 275 ), final pathologic diagnoses, different types of colon polypoid lesions (adenoma, hyperplastic, serrated adenoma, adenocarcinoma), and piecemeal resections (Table 3). Patients' age, when treated as a continuous variable and not dichotomized, was still not correlated with delayed bleeding $[\mathrm{r}(655)=0.078$, $p=0.278]$. Likewise, there was no correlation between delayed bleed and the number of clips used on a lesion $[\mathrm{r}(655)=-0.021, p=0.592]$.

\section{Logistic regressions predicting likelihood of delayed bleed associated with clinical and procedure-related features}

The first logistic regression model included lesion location (upper versus lower GI) and lesion size (mean centered) as predictors of delayed bleeding, along with two interaction terms (i.e. clip $\times$ lesion size; clip $\times$ location). There was no evidence that clip use (versus no clip use) moderated the effects of lesion size $(\mathrm{p}=0.954)$ or lesion location $(p=0.997)$ on the likelihood of a delayed bleed. Furthermore, a binary logistic regression in the lower GI subgroup to test whether clip use might serve as a moderator of any relationship between polyp location (right versus left colon) on the likelihood of delayed bleed showed that the effects of clip use, polyp location in the colon, and the interaction between these variables as predictors of delayed bleed were not statistically significant $\left[\mathrm{x}^{2}(3)=0.34, p=0.951\right]$. Binary logistic regressions for colon polypoid lesions (adenoma, hyperplastic, serrated adenoma, adenocarcinoma) to test whether clip use might moderate any possible effects of lesion type on delayed bleed showed that none of these models were

Table 3 Fisher's p-values and reported phi-coefficients associated with tests of the zero-order relationships between delayed bleeding and the variables

\begin{tabular}{|c|c|c|}
\hline Variable & Fisher's exact $p$-value & phi-coefficient $(\Phi)$ \\
\hline Clip use & 0.204 (one-sided) & -0.042 \\
\hline Lesion size ( $<20 \mathrm{~mm}$ versus $\geq 20 \mathrm{~mm}$ ) & 0.045 & 0.079 \\
\hline Lesion location (upper versus lower Gl) & 0.054 & -0.080 \\
\hline Aspirin Use & 1.00 & -0.005 \\
\hline NSAID use & 1.00 & -0.013 \\
\hline Coagulant use & 0.017 & 0.129 \\
\hline Anti-platelet use & 0.463 & 0.021 \\
\hline HTN & 1.00 & 0.003 \\
\hline DM & 1.00 & -0.002 \\
\hline$C A D$ & 0.416 & 0.036 \\
\hline CVA & 1.00 & -0.030 \\
\hline Cirrhosis & 1.00 & -0.025 \\
\hline ESRD & 0.222 & 0.060 \\
\hline Age at diagnosis (< 75 versus $\geq 75$ ) & 0.346 & 0.042 \\
\hline Ablation & 0.036 & 0.464 \\
\hline Piecemeal resection & 0.093 & 0.018 \\
\hline Adenoma (colon) & 1.000 & 0.011 \\
\hline Hyperplastic (colon) & 0.388 & 0.036 \\
\hline Serrated adenoma (colon) & 0.488 & -0.046 \\
\hline Adenocarcinoma (colon) & 0.231 & 0.055 \\
\hline
\end{tabular}


statistically significant as follows: clip use and adenoma $(p=0.755)$, clip use and hyperplastic polyps $(p=0.370)$, clip use and serrated adenoma $(p=0.765)$, clip use and adenocarcinoma $(p=0.347)$.

Logistic regression analyses also examined whether clip use modified the likelihood of delayed bleeding as related to the following variables: use of aspirin, NSAIDs, anti-coagulants, and anti-platelets (Model 1), pathologic diagnoses (Model 2), and whether ablation and piecemeal approach was used during a procedure (Model 3). None of the predictors in the models were statistically significant (model $1 p$-value $=0.348$, model 2 $\mathrm{p}$-value $=0.562$, model $3 \mathrm{p}$-value $=0.064)$.

\section{Exploratory analysis: predicting use of clips during procedures}

An exploratory analysis was used to predict the use of clips during procedures by the different endoscopists. Multilevel analysis showed that there is evidence of variation among endoscopists in their likelihood to use at least one clip during a procedure. Nevertheless, the candidate predictors (average age of patients, the number of previous procedures, and the average size and number of lesions across an endoscopists' procedures) were unrelated to clip use. In short, there are probably other undetermined factors associated with the endoscopists' decision tree that might account for the variable likelihood of using clips.

\section{Cost analysis}

Given that the total number of clips was 901 and the average cost of different clips used was $\$ 193$, the total cost of clips for prophylactic purposes was $\$ 173,893$. The actual additional cost incurred by clip usage is probably higher given that procedures that did not specify the number of clips were analyzed as having used 1 clip and the true clip number is likely to be higher. Since there was no statistically significant difference between clip use and several clinically-relevant variables (that have the potential to accrue additional medical cost) among the 18 patients who exhibited delayed bleeding (hospital length of stay, $p=0.725$; need for repeat procedure at the time of rebleed, $p=0.596$; and blood transfusion requirement, $p=0.332$ ), it can be assumed that $\$ 173,893$ is the majority of the direct costs of prophylactic clip usage, not including the indirect costs such as prolonged procedure time. None of the delayed bleeding cases required ICU admission, IR intervention, or surgery.

\section{Discussion}

The practice of prophylactic application of hemoclips for the prevention of delayed bleeding is increasing [30]. However, placement of hemoclips has been associated with mixed results in preventing delayed EMR bleeding and there are no uniform guidelines to support its routine application for this purpose. Furthermore, the cost of hemoclips are rather substantial with price range of \$ 125-277 per clip in the current market (average cost for the four different models of clips used for this study cohort was \$ 193), and this does not include added time spent to perform clip application thus raising concerns about the cost-effectiveness of routine prophylactic clip placement [25, 31]. Parikh et al. searched existing published data on post-polypectomy bleeding rates and performed a decision analysis to examine the cost-effectiveness of routine, prophylactic clip placement after colon polypectomy [31]. The researchers determined that prophylactic clip placement seems to be a costeffective strategy in patients who are taking anti-platelet or anti-coagulation medications at the time of the procedure. However, for those patients not receiving anti-platelet or anti-coagulation therapy, placement of prophylactic clips after polypectomy was not cost-effective, particularly for smaller sized polyps [31]. Dokoshi et al. conducted a randomized study on the effectiveness of prophylactic clipping during endoscopic resection of colon polyps for the prevention of delayed bleeding [26]. They concluded that there was no difference in delayed bleeding rates between patients who received prophylactic clipping and those who did not. In this particular study, anticoagulant treatment made no difference between the clip and non-clip group in delayed bleeding rates provided the anticoagulant was stopped prior to the procedure [26]. Mori et al. carried out a prospective trial comparing snare cauterization to clip closure for the prevention of post-EMR delayed bleed. They concluded that snare cauterization was superior to clip closure in terms of procedure time and medical costs. Moreover, their findings showed no difference in delayed bleeding between the two groups [27].

Our study is a large retrospective cohort study that examines the effect of hemoclip application in preventing delayed post-EMR bleed for both upper and lower GI tract lesions. There was no statistically significant association between delayed post-EMR bleeding and use of prophylactic hemoclips. The total cost of clips for prophylactic purposes was $\$ 173,893$ while there was no statistically significant difference between clip use and several clinicallyrelevant variables (hospital length of stay, need for repeat procedure at the time of rebleed, and blood transfusion requirement) that have the potential to accrue additional medical cost, meaning the amount listed here was the majority of the direct cost of prophylactic clip usage. Given these findings, one can then question if there is no place for prophylactic hemoclip placement at all in the setting of upper/lower EMR or certain subgroups within these EMR procedures. When we performed analyses on delayed bleeding rate in the context of different variables without taking clipping into consideration, delayed bleed 
did occur more frequently in those cases involving larger lesions (whether the lesion size was treated as a continuous variable or dichotomized as $<20 \mathrm{~mm}$ versus $\geq 20 \mathrm{~mm}$ ), lower GI lesions, anti-coagulant use and ablative method usage during EMR. When logistic regression was performed, however, we found that there was no evidence that clip use (versus no clip) moderated the effects of lesion size, lesion location (upper versus lower), anticoagulation use, usage of ablation, colon polyp location (right versus left) on the likelihood of delayed bleed. Therefore, one can perhaps suspect that prophylactic clipping may have a role in high-risk subgroups (larger lesions, lower GI lesions, anti-coagulation use, and ablation at the time of EMR) based on their higher rate of delayed bleeding, but our study did not show that hemoclip application in these cohorts resulted in lower delayed bleed.

The primary limitation of this study is its retrospective design, which did not allow ideal variable control between the two groups. Nonetheless, our secondary analyses addressing these variables did not change the overall result of the study. Another limitation is that the procedures were performed by multiple endoscopists with differences in training and technique. However, our post-hoc analysis showed that the inter-endoscopist factor does not change the primary outcome. It may be argued that the endoscopists used hemoclips primarily for the lesions that had increased of risk of bleeding. This type of information, i.e. endoscopist bias, would be hard to capture in a retrospective study. While it is possible that there may have been some bias toward using clips for those cases that the endoscopists thought had higher chance of bleeding based on lesion characteristics and/or patient characteristics, following reasons confirm that these biases were minimal. In terms of lesion characteristics, one information our study captured is the lesion size. We noted that those with no clips had larger lesion size (mean $27.10 \mathrm{~mm}$ ) compared to those with clips (mean $23.13 \mathrm{~mm}$ ), suggesting that the endoscopists did not necessarily feel compelled to use hemoclips for larger size lesions. For patient characteristics, there was no difference between clip versus no-clip groups in terms of gender, age, aspirin use, NSAID use, and anti-coagulation use. There was a difference in antiplatelet usage between two groups, but the no-clip group had a higher proportion of patients who used antiplatelets, meaning the endoscopists did not feel obliged to use clips more often in this cohort solely because they were on anti-platelets. Lastly, the number of clips used was unclear in some of the EMR procedures and thus the cost analysis was an estimation. However, given that we did not overestimate the number of clips in those unclear cases but instead underestimated the number of clips used, i.e. performed analyses of these "unclear" procedures as having only one clip, the actual additional cost incurred by clip usage is likely to be higher.
Our present study has several strengths as well. The integrated healthcare system of KPSC allows for a central database repository that yielded a large sample size and comprehensive data availability during the follow-up period after EMR. The Kaiser Permanente patient population is a rather diverse population of different geographical and ethnic backgrounds, which supports these study results being more generalizable. Lastly, our data includes both upper and lower gastrointestinal tract lesions whereas the majority of the studies that have examined the prophylactic use of hemoclips for EMR were restricted to the lower GI system.

There is a paucity of large, randomized controlled trials (RCT) that specifically examine the cost-effectiveness of prophylactic hemoclip utilization for both upper and lower EMR, but several recent RCTs, published after the completion of our study, on the usage of hemoclips to prevent delayed bleeding (DB) after resection of colon lesions may be worth mentioning. First of these studies was by Pohl et al. examining large nonpedunculated colon polyp ( $\geq 20 \mathrm{~mm}$ ) that underwent endoscopic closure with a clip or no closure [32]. The protective effect of clip closure of the mucosal defect in reducing the risk of $\mathrm{DB}$ appeared to be restricted to the proximal colon lesions; there was actually higher delayed bleeding in distal colon lesions in the clip group. Subsequently, a study by Albeniz et al. also included nonpedunculated colon polyps measuring $\geq 20 \mathrm{~mm}$ but with substantial DB risk, i.e. $>90 \%$ of the cases were proximal polyps, $51 \%$ were $>40 \mathrm{~mm}$, and $36 \%$ of the patients were on antiplatelets [33]. Intention to treat (ITT) analysis showed a trend for lower DB in clip group. In per protocol (PP) analysis, DB was significantly lower in complete clip closure group (as opposed to the partial closure subgroup and the failed closure subgroup). However, these polyps that were successfully clipped were also smaller, had better accessibility, and in shorter and easier EMR procedures. Contrary to the result of these two studies mentioned, the study by Feagins et al. showed no statistical difference in $\mathrm{BD}$ between hemoclip group and no hemoclip group in their cohort of 1098 patients [30]. As opposed to the Pohl study, they found no difference in bleed rates between proximal polyps that underwent prophylactic hemoclip placement versus no prophylactic hemoclip. While these recent RCTs have overcome one of the limitations of our study, its retrospective design, our study still has an advantage since it includes both upper GI and lower GI/colon lesions. Also, unlike the study by Albeniz et al., which included only high-risk lesions, our study included all lesions regardless of their risk status, and this may potentially make our study more generalizable for all EMRs. The Feagins study supports the findings of our results that the prophylactic placement of hemoclips does not affect the proportion of $\mathrm{DB}$, also questioning the widespread, expensive practice of routinely placing prophylactic hemoclips after polyp resection. 


\section{Conclusion}

In conclusion, prophylactic hemoclip application did not appear to result in decreased delayed post-EMR bleed for upper and lower GI tract lesions in this retrospective analysis. Given this result and the cost of hemoclips, routine prophylactic clip application during EMR may incur high healthcare costs without consistently demonstrable clinical gains. The practice of healthcare is constantly changing to incorporate more cost-effective care, and thus the outcomes of this study have important implications.

\section{Abbreviations \\ ASA: American Society of Anesthesiologist; CAD: Coronary artery disease; CVA: Cerebrovascular accident; DB: Delayed bleeding; DM: Diabetes; EGD: Esophagogastroduodenoscopy; EMR: Endoscopic mucosal resection; ESCA: post-EMR scar clip artifact; ESRD: End stage renal disease; Gl: Gastrointestinal; Hb: Hemoglobin; HTN: Hypertension; ICU: Intensive Care Unit; IR: Interventional radiology; KPSC: Kaiser Permanente Southern California; LOS: Length of stay; NSAIDs: Non-steroidal anti-inflammatory drugs; RCT: Randomized controlled trial}

\section{Acknowledgements}

Not applicable.

\section{Authors' contributions}

$\mathrm{BL}$ is the principal investigator and spearheaded study design with KK1 as co-investigator. $\Pi$, AN, KC, MA, BL, AG1, CC contributed to data acquisition and data analysis. KK1, RA, CC, TD, AG2, GH, Jl, KK2, BL all contributed their EMR procedure data. HMC and $A B$ ran the statistical analysis. KK1, $A B, R A, C C$, $\mathrm{TD}, \mathrm{AG} 2, \mathrm{GH}, \mathrm{Jl}, \mathrm{KK} 2, \mathrm{BL}$ helped interpret the data. All authors critically revised the manuscript and all authors approved the final version of the manuscript. $\mathrm{BL}$ supervised the study.

\section{Funding}

No funding was provided for this study.

\section{Availability of data and materials}

The datasets used and/or analysed during the current study are available from the corresponding author on reasonable request.

\section{Ethics approval and consent to participate}

The study was approved by the Kaiser Permanente Southern California (KPSC) Institutional Review Board (protocol number 10830). Waiver of individual patient informed consent was obtained from KPSC Institutional Review Board.

\section{Consent for publication}

Not applicable.

\section{Competing interests}

The authors declare that they have no competing interests.

\section{Author details}

'Department of Internal Medicine, School of Medicine, University of California, Riverside, 900 University Avenue, Riverside, CA 92521, USA. 2Department of Gastroenterology, Kaiser Permanente Los Angeles Medical Center, 4867 W Sunset Blvd, Los Angeles, CA 90027, USA. ${ }^{3}$ Department of Educational Psychology, The University of Oklahoma, 820 Van Vleet Oval, Collings Hall, Room 321, Norman, OK 73019-2041, USA. ${ }^{4}$ Department of Gastroenterology, Kaiser Permanente Downey Medical Center, 9353 Imperial Highway, Downey, CA 90242, USA. ${ }^{5}$ Department of Gastroenterology, Kaiser Permanente Riverside Medical Center, 10800 Magnolia Avenue, Riverside, CA 92505, USA. ${ }^{6}$ Department of Gastroenterology, Kaiser Permanente Orange County Medical Center, 3440 E La Palma Avenue, Anaheim, CA 92806, USA. ${ }^{7}$ Department of Gastroenterology, Kaiser Permanente San Diego Medical Center, 9445 Clairemont Mesa Blvd, San Diego, CA 92123, USA.
Received: 7 August 2019 Accepted: 20 February 2020

Published online: 06 March 2020

\section{References}

1. Longcroft-Wheaton G, Duku M, Mead R, Basford P, Bhandari P. Risk stratification system for evaluation of complex polyps can predict outcomes of endoscopic mucosal resection. Dis Colon Rectum. 2013;56(8):960-6.

2. Repici A, Pellicano R, Strangio G, Danese S, Fagoonee S, Malesci A. Endoscopic mucosal resection for early colorectal neoplasia: pathologic basis, procedures, and outcomes. Dis Colon Rectum. 2009;52(8):1502-15.

3. Swan MP, Bourke MJ, Alexander S, Moss A, Williams SJ. Large refractory colonic polyps: is it time to change our practice? A prospective study of the clinical and economic impact of a tertiary referral colonic mucosal resection and polypectomy service (with videos). Gastrointest Endosc. 2009;70(6): $1128-36$

4. Hassan C, Repici A, Sharma P, et al. Efficacy and safety of endoscopic resection of large colorectal polyps: a systematic review and meta-analysis. Gut. 2016;65(5):806-20.

5. De Ceglie A, Hassan C, Mangiavillano B, et al. Endoscopic mucosal resection and endoscopic submucosal dissection for colorectal lesions: a systematic review. Crit Rev Oncol Hematol. 2016;104:138-55.

6. Rao AK, Soetikno R, Raju GS, et al. Large sessile serrated polyps can be safely and effectively removed by endoscopic mucosal resection. Clin Gastroenterol Hepatol. 2016;14(4):568-74.

7. Albéniz E, Fraile $M$, Ibáñez $B$, et al. A scoring system to determine risk of delayed bleeding after endoscopic mucosal resection of large colorectal lesions. Clin Gastroenterol Hepatol. 2016;14(8):1140-7.

8. Burgess NG, Williams SJ, Hourigan LF, et al. A management algorithm based on delayed bleeding after wide-field endoscopic mucosal resection of large colonic lesions. Clin Gastroenterol Hepatol. 2014;12(9):1525-33.

9. Fisher DA, Maple JT, Ben-Menachem T, et al. Complications of colonoscopy. Gastrointest Endosc. 2011;74(4):745-52.

10. Levin TR, Zhao W, Conell C, et al. Complications of colonoscopy in an integrated health care delivery system. Ann Intern Med. 2006;145(12):880-6.

11. Day LW, Kwon A, Inadomi JM, Walter LC, Somsouk M. Adverse events in older patients undergoing colonoscopy: a systematic review and metaanalysis. Gastrointest Endosc. 2011;74(4):885-96.

12. Rabeneck L, Saskin R, Paszat LF. Onset and clinical course of bleeding and perforation after outpatient colonoscopy: a population-based study Gastrointest Endosc. 2011;73(3):520-3.

13. Crispin A, Birkner B, Munte A, Nusko G, Mansmann U. Process quality and incidence of acute complications in a series of more than 230,000 outpatient colonoscopies. Endoscopy. 2009;41(12):1018-25.

14. Ko CW, Riffle $S$, Michaels $L$, et al. Serious complications within 30 days of screening and surveillance colonoscopy are uncommon. Clin Gastroenterol Hepatol. 2010;8(2):166-73.

15. Rathgaber SW, Wick TM. Colonoscopy completion and complication rates in a community gastroenterology practice. Gastrointest Endosc. 2006;64(4):556-62.

16. Koh R, Hirasawa K, Yahara S, et al. Antithrombotic drugs are risk factors for delayed postoperative bleeding after endoscopic submucosal dissection for gastric neoplasms. Gastrointest Endosc. 2013;78(3):476-83.

17. Watabe H, Yamaji Y, Okamoto M, et al. Risk assessment for delayed hemorrhagic complication of colonic polypectomy: polyp-related factors and patient-related factors. Gastrointest Endosc. 2006;64(1):73-8.

18. Buddingh $\mathrm{KT}$, Herngreen $\mathrm{T}$, Haringsma J, et al. Location in the right hemicolon is an independent risk factor for delayed post-polypectomy hemorrhage: a multi-center case-control study. Am J Gastroenterol. 2011; 106(6):1119-24.

19. Singh M, Mehta N, Murthy UK, Kaul V, Arif A, Newman N. Postpolypectomy bleeding in patients undergoing colonoscopy on uninterrupted clopidogrel therapy. Gastrointest Endosc. 2010;71(6):998-1005.

20. Liaquat H, Rohn E, Rex DK. Prophylactic clip closure reduced the risk of delayed postpolypectomy hemorrhage: experience in 277 clipped large sessile or flat colorectal lesions and 247 control lesions. Gastrointest Endosc. 2013;77(3):401-7.

21. Zhang QS, Han B, Xu JH, Gao P, Shen YC. Clip closure of defect after endoscopic resection in patients with larger colorectal tumors decreased the adverse events. Gastrointest Endosc. 2015:82(5):904-9.

22. Choi KD, Jung HY, Lee $\mathrm{GH}$, et al. Application of metal hemoclips for closure of endoscopic mucosal resection-induced ulcers of the stomach to prevent delayed bleeding. Surg Endosc. 2008;22(8):1882-6. 
23. Shioji K, Suzuki Y, Kobayashi M, et al. Prophylactic clip application does not decrease delayed bleeding after colonoscopic polypectomy. Gastrointest Endosc. 2003;57(6):691-4.

24. Quintanilla E, Castro $\mathrm{L}$, Rábago $L R$, et al. Is the use of prophylactic hemoclips in the endoscopic resection of large pedunculated polyps useful? A prospective and randomized study. J Interv Gastroenterol. 2012; 2(4):183-8.

25. Feagins LA, Nguyen AD, Iqbal R, Spechler SJ. The prophylactic placement of hemoclips to prevent delayed postpolypectomy bleeding: an unnecessary practice? A case control study. Dig Dis Sci. 2014;59(4):823-8.

26. Dokoshi T, Fujiya M, Tanaka K, et al. A randomized study on the effectiveness of prophylactic clipping during endoscopic resection of colon polyps for the prevention of delayed bleeding. Biomed Res Int. 2015;2015: 490272.

27. Mori H, Kobara H, Nishiyama N, et al. Simple and reliable treatment for postEMR artificial ulcer floor with snare cauterization for 10- to 20-mm colorectal polyps: a randomized prospective study (with video). Surg Endosc. 2015; 29(9):2818-24

28. Bahin FF, Rasouli KN, Williams SJ, Lee EY, Bourke MJ. Prophylactic clipping for the prevention of bleeding following wide-field endoscopic mucosal resection of laterally spreading colorectal lesions: an economic modeling study. Endoscopy. 2016;48(8):754-61.

29. Namasivayam V, Wang KK, Prasad GA. Endoscopic mucosal resection in the Management of Esophageal Neoplasia: current status and future directions. Clin Gastroenterol Hepatol. 2010;8(9):743-54.

30. Feagins LA, Smith AD, Kim D, et al. Efficacy of prophylactic Hemoclips in prevention of delayed post-polypectomy bleeding in patients with large colonic polyps. Gastroenterology. 2019;157(4):967-76.

31. Parikh ND, Zanocco K, Keswani RN, Gawron AJ. A cost efficacy decision analysis of prophylactic clip placement after endoscopic removal of large polyps. Clin Gastroenterol Hepatol. 2013;11(10):1319-24.

32. Pohl H, Grimm IS, Moyer MT, et al. Clip closure prevents bleeding after endoscopic resection of large colon polyps in a randomized trial. Gastroenterology. 2019;157(4):977-84.

33. Albéniz E, Álvarez MA, Espinós JC, et al. Clip closure after resection of large colorectal lesions with substantial risk of bleeding. Gastroenterology. 2019; 157(5):1213-21.

\section{Publisher's Note}

Springer Nature remains neutral with regard to jurisdictional claims in published maps and institutional affiliations.

Ready to submit your research? Choose BMC and benefit from:

- fast, convenient online submission

- thorough peer review by experienced researchers in your field

- rapid publication on acceptance

- support for research data, including large and complex data types

- gold Open Access which fosters wider collaboration and increased citations

- maximum visibility for your research: over $100 \mathrm{M}$ website views per year

At $\mathrm{BMC}$, research is always in progress.

Learn more biomedcentral.com/submissions 